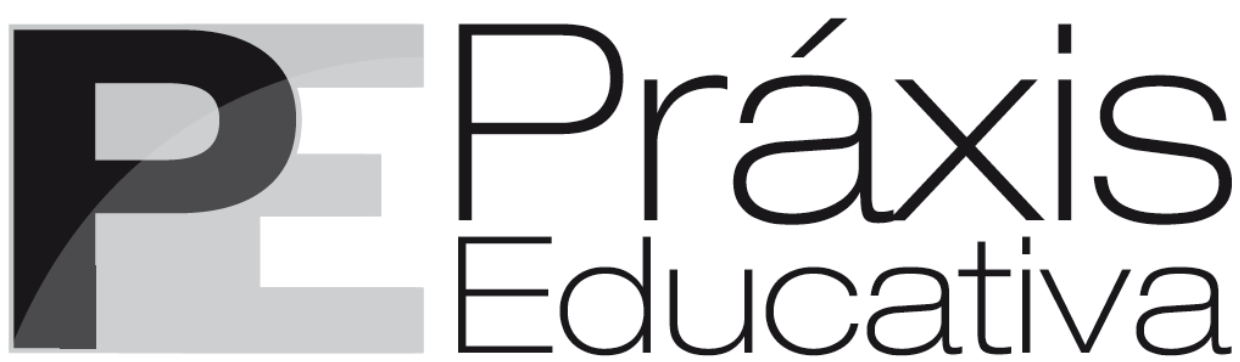

ISSN 1809-4031

elSSN 1809-4309

http://dx.doi.org/10.5212/PraxEduc.v.14n3.001

\title{
Promessas e trajetórias da Educação Inclusiva: notas críticas sobre pesquisas futuras voltadas a uma ideia venerável*
}

\section{Inclusive Education's promises and trajectories: critical notes about future research on a venerable idea}

\section{Promesas y caminos de la Educación Inclusiva: notas críticas sobre la investigación futura hacia una idea venerable}

\author{
Alfredo J. Artiles* \\ Elizabeth B. Kozleski**
}

Resumo: O objetivo deste artigo é oferecer notas críticas sobre pesquisa em educação inclusiva nos Estados Unidos da América. Discutimos questões pertinentes sobre a clareza conceitual e as formas pelas quais a educação inclusiva interage com reformas que compartilham objetivos de equidade, observando as rupturas e as consequências não intencionais que surgem no nexo dessas reformas. Além disso, identificamos desafios e paradoxos duradouros nesta revisão de literatura. Estes incluem questões de amostragem, uma ênfase no local onde os alunos são alocados como representantes da educação inclusiva

\footnotetext{
* Este artigo foi originalmente publicado em Education Policy Analysis Archives, v. 24, n. 43, 2016. Está sendo publicado com autorização dos autores e do periódico. Tradução de Janete Bridon. Revisão técnica de Márcia Denise Pletsch. Os autores reconhecem o apoio parcial da Concessão \# H325Y120005, o SWIFT Center, na produção deste artigo. As opiniões aqui expressas não representam necessariamente as posições ou políticas do Departamento de Educação ou do SWIFT Center. Nenhum endosso oficial do Departamento de Educação dos EUA de qualquer produto, mercadoria, serviço ou empresa mencionado nesta publicação é intencional ou deve ser inferido. Todas as análises e interpretações fazem parte do trabalho dos autores.

** É Dean of the Graduate College e "Ryan C. Harris Professor of Special Education" na Arizona State University. Seus estudos acadêmicos investigam as desigualdades educacionais relacionadas às interseções de deficiência com diferenças socioculturais. Ele codirige a Equity Alliance e foi vice-presidente da American Educational Research Association (AERA). O Dr. Artiles edita a série de livros Disability, culture, \& equity (Deficiência, cultura e equidade) da Teachers College Press. Ele recebeu o Prêmio Palmer O. Johnson de 2012 pelo melhor artigo publicado em um periódico da AERA. O Dr. Artiles é membro da Comissão Consultiva do Presidente Obama sobre Excelência Educacional para Hispânicos. E-mail: <alfredo.artiles@asu.edu>. ORCID: http://orcid.org/0000-0001-5772-0787

*** Diretora de Educação Especial da University of Kansas, conduz pesquisas sobre questões de equidade e justiça na educação inclusiva e na aprendizagem profissional. Os prêmios recentes incluem a Cátedra da UNESCO em Pesquisa Internacional Inclusiva, o prêmio TED-Merrill de liderança em educação de professores de educação especial e o prêmio Scholar of the Century da University of Northern Colorado. Livros recentes incluem Ability, equity, and culture (Habilidade, equidade e cultura) e Inclusive Education: examining equity on five continents (Educação Inclusiva: examinando a equidade nos cinco continentes. E-mail: <elizabeth.kozleski@ku.edu>. ORCID: https://orcid.org/0000-0003-0290-935X
}

Práxis Educativa, Ponta Grossa, v. 14, n. 3, p. 804-831, set./dez. 2019 Disponível em: <http://www.revistas2.uepg.br/index.php/praxiseducativa> 
em face de uma educação inclusiva como transformação dos sistemas educacionais, as maneiras pelas quais as medições de resultados foram examinadas nesta pesquisa, e a necessidade e os desafios da construção de alianças estratégicas que poderiam promover uma agenda de educação inclusiva. Concluímos com reflexões e sugestões para um futuro programa de pesquisa que inclua aprimorar a identidade da inclusão, atendendo à natureza fluida das diferenças de habilidades e das múltiplas identidades dos alunos, de modo a ampliar a unidade de análise para sistemas de atividades e documentar processos e resultados.

Palavras-chave: Educação inclusiva. Equidade educacional. Deficiência e diferença.

\begin{abstract}
The purpose of this article is to offer critical notes on inclusive education research in the U.S. We discuss issues germane to conceptual clarity and the ways in which inclusive education interacts with reforms that share equity goals, noting disruptions and unintended consequences that arise at the nexus of these reforms. In addition, we identify enduring challenges and paradoxes in this research literature. These include sampling issues, an emphasis on where students are placed as a proxy for inclusive education vis-àvis inclusive education as the transformation of educational systems, the ways in which outcome measures have been examined in this research, and the need for and challenges of building strategic alliances that could advance an inclusive education agenda. We conclude with reflections and suggestions for a future research program that include sharpening inclusion's identity, attending to the fluid nature of ability differences and students' multiple identities, broadening the unit of analysis to systems of activities, and documenting processes and outcomes.
\end{abstract}

Keywords: Inclusive education. Educational equity. Disability and difference.

Resumen: El propósito de este artículo es proporcionar notas críticas sobre la investigación en educación inclusiva en los Estados Unidos. Discutimos preguntas pertinentes sobre la claridad conceptual y las formas en que la educación inclusiva interactúa con reformas que comparten objetivos de equidad, observando las interrupciones y las consecuencias no deseadas que surgen en el nexo de estas reformas. Además, identificamos desafíos y paradojas duraderas en esta revisión de la literatura. Estos incluyen preguntas de muestreo, un énfasis en dónde se asignan los estudiantes como representantes de la educación inclusiva frente a la educación inclusiva como una transformación de los sistemas educativos, las formas en que se han examinado las medidas de resultado en esta investigación, y la necesidad y desafíos de construir alianzas estratégicas que puedan promover una agenda de educación inclusiva. Concluimos con reflexiones y sugerencias para un programa futuro de investigación que incluye mejorar la identidad de inclusión, teniendo en cuenta la naturaleza fluida de las diferencias de habilidades e identidades múltiples de los estudiantes, con el fin de ampliar la unidad de análisis a los sistemas de actividades y documentar procesos y resultados.

Palabras clave: Educación inclusiva. Equidad educativa. Deficiencia y diferencia.

\title{
Introdução
}

Poucas ideias têm recebido mais elogios e respostas entusiastas nos mundos da política educacional, da pesquisa e da prática do que a educação inclusiva. No entanto, ironicamente, poucas ideias têm sido criticadas e resistidas como essa noção. De fato, a educação inclusiva tem provocado respostas contraditórias de profissionais, pesquisadores e políticos (SLEE, 2011). Contudo, pode-se argumentar que o contencioso que caracterizou os primeiros anos deste movimento educacional tem diminuído nos últimos anos. Os debates sobre os méritos e a viabilidade da educação inclusiva dos anos de 1990 parecem ter diminuído, e a ideia de educação inclusiva parece permear políticas, legislações e programas de preparação profissional nos EUA. Por outro lado, o que falta nesta literatura é uma discussão crítica das promessas originais da educação inclusiva em face dos paradoxos que estão emergindo na implementação contemporânea desse movimento, particularmente quando a educação inclusiva cruza com outros esforços de reforma da educação orientados para a equidade. O objetivo deste ensaio é

Práxis Educativa, Ponta Grossa, v. 14, n. 3, p. 804-831, set./dez. 2019 Disponível em: <http://www.revistas2.uepg.br/index.php/praxiseducativa> 
Promessas e trajetórias da Educação Inclusiva: notas críticas sobre pesquisas futuras...

apresentar uma crítica à pesquisa sobre educação inclusiva nos EUA, sua conceituação e trajetórias. Oferecemos recomendações para pesquisas futuras sobre esse tema que envolvam os limites e os desafios desse movimento. Entretanto, antes de apresentarmos essa análise e recomendações, situamos o estudo de educação inclusiva em uma perspectiva histórica.

\section{Uma breve história de uma ideia e de um movimento: uma noção voltada à justiça em busca de significado}

As origens da educação inclusiva eram ambiciosas, de longo alcance e fundamentadas em uma agenda de justiça explícita (ex. RYNDAK; FISHER, 1988). Em parte, a proposta de inclusão para transformar sistemas educacionais inteiros emergiu de uma crescente conscientização e crítica das desigualdades educacionais que haviam sido historicamente incorporadas nas condições socioeconômicas e culturais das nações (FERGUSON; KOZLESKI; SMITH, 2003; SAILOR; GEE; KARASOFF, 1993). Um objetivo explícito desses esforços era alcançar o que David Labaree (1997) descreveu como a abordagem da igualdade democrática à educação - isto é, "education is seen as a public good, designed to prepare people for political roles" (LABAREE, 1997, p. 42).

A base lógica da inclusão era romper as suposições, as práticas, as ferramentas e as políticas que privilegiavam certos grupos de estudantes e outros desfavorecidos (SKRTIC, 1995). Assim, o desafio era projetar e implementar sistemas educacionais que respondessem às características, às necessidades e aos interesses dos estudantes que representam o espectro mais amplo da variabilidade humana. Os caminhos de aprendizado e de desenvolvimento mediados por status socioeconômico, gênero, linguagem, nível de habilidade, raça e etnia, entre outros, seriam abordados e aproveitados em sistemas educacionais inclusivos. Nesse sentido, a educação inclusiva tendia a enfatizar um dos dois aspectos que constituem uma abordagem de igualdade democrática, a saber, "igualdade relativa", na qual a desigualdade social é minimizada para garantir que todos sejam considerados iguais (LABAREE, 1997) ${ }^{2}$. Com base nessas premissas, a maioria dos acadêmicos e profissionais concordaria que a educação inclusiva está preocupada com a transformação das culturas escolares para (1) aumentar o acesso (ou presença) de todos os alunos (não apenas grupos marginalizados ou vulneráveis), (2) melhorar a aceitação de todos os alunos por parte dos funcionários da escola e dos estudantes, (3) maximizar a participaşão dos estudantes em vários domínios de atividade, e (4) aumentar o desempenho de todos os alunos (ARTILES et al., 2006, p. 67).

O discurso sobre educação inclusiva que se originou em nações desenvolvidas no hemisfério ocidental espalhou-se por regiões geográficas ao ponto de ser descrito como uma "agenda global" (PIJL; MEIJER; HEGARTY, 1997). Esse movimento internacional foi moldado, entre outras forças, pela Declaração de Salamanca em 1994. Essa declaração histórica foi amplamente baseada em um discurso de direitos para abordar as necessidades educacionais dos estudantes, a saber (Organização das Nações Unidas para a Educação, a Ciência e a Cultura [UNESCO], 1994, p. 1):

\footnotetext{
${ }^{1}$ Tradução: [...] a educação é vista como um bem público, projetada para preparar as pessoas para papéis políticos.

${ }^{2} \mathrm{O}$ segundo aspecto de uma meta de igualdade democrática, "cidadania efetiva" (isto é, a educação como um meio de preparar pessoas com competência política como cidadãos) recebeu menos atenção no movimento de educação inclusiva.
}

Práxis Educativa, Ponta Grossa, v. 14, n. 3, p. 804-831, set./dez. 2019 Disponível em: <http://www.revistas2.uepg.br/index.php/praxiseducativa> 
Acreditamos e Proclamamos que:

- toda criança tem direito fundamental à educação, e deve ser dada a oportunidade de atingir e manter o nível adequado de aprendizagem,

- toda criança possui características, interesses, habilidades e necessidades de aprendizagem que são únicas,

- sistemas educacionais deveriam ser designados e programas educacionais deveriam ser implementados no sentido de se levar em conta a vasta diversidade de tais características e necessidades,

- aqueles com necessidades educacionais especiais devem ter acesso à escola regular, que deveria acomodá-los dentro de uma Pedagogia centrada na criança, capaz de satisfazer a tais necessidades,

- escolas regulares que possuam tal orientação inclusiva constituem os meios mais eficazes de combater atitudes discriminatórias criando-se comunidades acolhedoras, construindo uma sociedade inclusiva e alcançando educação para todos; além disso, tais escolas provêm uma educação efetiva à maioria das crianças e aprimoram a eficiência e, em última instância, o custo da eficácia de todo o sistema educacional.

Nos EUA, a educação inclusiva está mais intimamente ligada a uma disposição específica do Individuals with Disabilities Education Act ([IDEA], 2004) (Lei Educacional para Indivíduos com Deficiência), a cláusula do Ambiente Menos Restritivo. Nessa cláusula, que foi incluída na lei desde que foi originalmente aprovada em 1975, estabelece-se que, na medida do possível, as crianças com deficiência, incluindo crianças em instituições públicas ou privadas ou outras instalações de cuidados, devem receber formação em ambientes menos restritivos. Além disso, a cláusula estipula que, somente quando a formação em classes regulares com o uso de ajuda e de serviços suplementares não pode ser alcançada satisfatoriamente, as crianças deveriam receber formação em outro lugar. Os defensores da educação inclusiva argumentam que, como é possível fornecer ajuda e serviços suplementares necessários, essa seção da IDE $A$ fornece a justificativa legal para a educação inclusiva em todas as escolas nos EUA. Vários processos judiciais esclareceram aspectos dessa cláusula (YELL, 2015), encontrando um meio termo entre posicionamentos e estágios totalmente inclusivos que impedem o acesso de alunos com deficiências e a oportunidade de vivenciar a escola com seus pares típicos.

A agenda de justiça original incorporada no movimento de inclusão foi enquadrada como uma questão de direitos individuais e conectada ao acesso, à participação e/ou aos resultados. Skrtic (1991), entretanto, apontou que múltiplos discursos circulam nos círculos de política, de pesquisa e de prática ao longo da história da inclusão, e afirmamos que cada um desses discursos favorece diferencialmente paradigmas de justiça particulares que têm implicações para as agendas de reforma e sua implementação.

Skrtic (1995) identificou discursos preocupados com dois grandes temas, a saber: a justificação e a implementação da inclusão nos EUA nos anos de 1980 e 1990 (ver também DYSON, 1999). A lógica do discurso da justificação foi fundamentada no que foi descrito como uma perspectiva de direitos e ética. A educação inclusiva justificou-se, segundo esse discurso, porque a educação especial não apresentou impacto positivo sobre as taxas de desenvolvimento e aprendizagem de alunos com necessidades educacionais especiais. Esse foi um argumento contencioso, uma vez que os dados disponíveis foram misturados, e os debates se seguiram às evidências citadas para apoiar ou contrariar essa crítica (GRAFF; KOZLESKI, 2014). Observe-se que o discurso da educação inclusiva mudou de uma visão que engloba todos os alunos para um foco em alunos com deficiências ${ }^{3}$ (voltaremos a esse ponto em uma seção subsequente deste

\footnotetext{
${ }^{3}$ Para fins estilísticos, usamos uma linguagem intercambiável em primeira pessoa (ou seja, alunos com deficiências) e termos alinhados ao modelo social de deficiência (isto é, alunos com deficiência) para reconhecer a dimensão individual da deficiência, bem como os papéis que a sociedade e as instituições desempenham em construir incapacidades.
}

Práxis Educativa, Ponta Grossa, v. 14, n. 3, p. 804-831, set./dez. 2019 Disponível em: <http://www.revistas2.uepg.br/index.php/praxiseducativa> 
Promessas e trajetórias da Educação Inclusiva: notas críticas sobre pesquisas futuras...

artigo). A crítica de eficácia para justificar a educação inclusiva foi baseada em um argumento da justiça distributiva em que o acesso a oportunidades educacionais era primordial (ARTILES; HARRIS-MURRI; ROSTENBERG, 2006).

O discurso sobre a implementação da inclusão foi indexado em pelo menos duas formas alternativas: (a) argumentos para se engajar em lutas políticas como veículo de mudança; e (b) considerações pragmáticas. Analisadores argumentaram que a educação inclusiva não poderia se tornar uma realidade a menos que deliberações e lutas políticas acontecessem para desmantelar o sistema educacional tradicional que excluía estudantes com necessidades educacionais especiais e com deficiências. Outros estudiosos estavam preocupados com questões práticas pertinentes a programas e escolas; ou seja, com questões relacionadas ao design da inclusão, características e práticas cotidianas de preparação curricular, pedagógica, de avaliação e profissional (ARTILES et al., 2006). Essa visão pragmática dentro do discurso de implementação representa a maior parte da literatura sobre educação inclusiva. Dada a natureza de múltiplas vozes do movimento de inclusão, não é de surpreender que suas usadas aspirações viajassem através das localidades e do tempo com significados díspares e com consequências alternativas (SRIVASTAVA; DE BOER; PIJL, 2015).

O apoio consistente da UNESCO ressalta o grau em que a agenda da educação inclusiva é internacional por natureza. O movimento culminou na Convenção das Nações Unidas sobre os Direitos das Pessoas com Deficiência (CDPD) (2006), que (em 2016) já foi assinada por 160 nações e pela União Europeia. Particularmente, os EUA não assinaram.

Alguns argumentam que o movimento de educação inclusiva falha em reconhecer sua aplicação desigual entre as categorias raciais, de gênero, religiosa, linguística, de nacionalidade e de classe que existem dentro e através das fronteiras nacionais (ARTILES; KOZLESKI; GONZALEZ, 2011). Como resultado, muitas crianças rotuladas para a educação especial são membros de grupos minoritários raciais, étnicos, linguísticos e culturais (ARTILES; KOZLESKI; WAITOLLER, 2011; KOZLESKI; YU, 2016). Embora a educação inclusiva tenha se tornado global, como refletido no número de signatários comprometidos com os ideais incorporados na Declaração de Salamanca (ex. 92 nações e 25 agências internacionais), bem como a CDPD, é importante notar que quando o olhar analítico desce aos níveis locais, a educação inclusiva adota sabores locais únicos. Artiles e Dyson (2005) abordaram essa questão no contexto da crescente influência da globalização nas políticas e práticas educacionais. Eles reconheceram que as forças da globalização não são necessariamente adversas; eles argumentam que o risco de um impacto negativo é exacerbado quando nós "overlook legitimate local differences. [These local differences may reside] in the ways rights are understood in different cultural contexts, differences in the roles ascribed to education, differences in forms and processes of exclusion, or simply in differences in what is practicable"4 (ARTILES; DYSON, 2005, p. 42).

Em suma, uma leitura crítica dessa literatura sugere que existe uma distância substancial entre a conceituação da educação inclusiva e sua implementação. Muitas políticas e proclamações adotaram uma retórica abrangente apoiada por uma visão de direitos universais, embora as interações locais desse movimento em contextos culturais tenham muitas vezes colidido com suas ambições de padronização (McDERMOTT; EDGAR; SCARLOSS, 2011; SLEE, 2011). A breve discussão precedente sobre a história e os significados da educação inclusiva serve de pano de fundo para uma análise das lacunas e dos paradoxos raramente reconhecidos na literatura

\footnotetext{
4 Tradução: ignoramos as diferenças locais legítimas. [Essas diferenças locais podem encontrar-se] nas formas como os direitos são compreendidos em diferentes contextos culturais, diferenças nos papéis atribuídos à educação, diferenças nas formas e nos processos de exclusão, ou simplesmente nas diferenças do que é praticável.
}

Práxis Educativa, Ponta Grossa, v. 14, n. 3, p. 804-831, set./dez. 2019 Disponível em: <http://www.revistas2.uepg.br/index.php/praxiseducativa> 
sobre educação inclusiva. Concluímos com reflexões para orientar pesquisas futuras sobre esse importante tópico.

\section{Um olhar mais próximo à pesquisa de inclusão dos estados unidos: lidando com promessas, lacunas e paradoxos}

Historicamente, a maior parte dos estudos sobre educação inclusiva gira em torno da inclusão de alunos com rótulos de deficiência em contextos de educação regular. Isso se reflete no discurso dos estudos publicados nos periódicos de educação especial mais visíveis dos EUA, incluindo, entre outros, Exceptional Children, Journal of Learning Disabilities, Journal of Special Education, Research and Practice for Persons with Severe Disabilities, e Remedial and Special Education. Para os propósitos deste ensaio crítico, baseamo-nos na narrativa dominante dos EUA para explorar como a educação inclusiva foi posicionada, descrita e criticada. Estamos cientes de que essa visão difere das narrativas alternativas de inclusão que foram amplamente elaboradas em disciplinas além da educação, embora pontos de vista alternativos também tenham sido produzidos dentro da educação. Essas perspectivas alternativas foram publicadas em revistas interdisciplinares dentro e fora dos EUA.

Usamos nosso conhecimento e envolvimento de longa data com a literatura de pesquisa em educação inclusiva para identificar quatro temas. Isso não pretende ser uma lista exaustiva de temas sobre lacunas e contradições. No entanto, consideramos esses temas como centrais para uma compreensão desse movimento. Os temas baseiam-se em revisões sistemáticas anteriores da pesquisa que realizamos na última década (ARTILES et al., 2006; KOZLESKI; YU, 2016; WAITOLLER; ARTILES, 2013), bem como em nossa experiência com pesquisas e trabalho de assistência técnica sobre questões de equidade em educação inclusiva e especial (ex.: ARTILES; KOZLESKI; WAITOLLER, 2011; KLINGNER et al., 2005; KOZLESKI; THORIUS, 2013). O primeiro tema diz respeito a quem está incluído como participante na pesquisa em educação inclusiva. De interesse foi a estreita faixa de alunos representados em pesquisas sobre educação inclusiva. Um segundo tema alude à importância de uma geografia da inclusão. Isto é, onde os alunos foram educados tornou-se mais importante do que o que e como aprenderam e os sistemas em que foram educados. Terceiro, levantamos questões e refletimos sobre a identidade da educação inclusiva em relação ao seu propósito e à sua função. Finalmente, discutimos as interseções da educação inclusiva com outras reformas da justiça e suas consequências não intencionais.

\section{De todos a certos grupos: amostragem em estudos de educação inclusiva}

Não obstante as ambiguidades de significado e as inúmeras conceituações de educação inclusiva, a definição oferecida na introdução deste manuscrito sugere que a educação inclusiva está preocupada com um ambicioso projeto de transformação educacional. A educação inclusiva aspira a mudar sistemas inteiros para melhorar o acesso educacional, a participação e os resultados para estudantes de todas as origens, independentemente de qualquer forma de diferença que os estudantes supostamente incorporem.

Apesar dessas aspirações louváveis, a maioria das pesquisas de inclusão nos EUA enfoca principalmente estudantes com deficiências (ARTILES et al., 2006). Isso também foi observado no âmbito internacional (ARTILES; KOZLESKI; WAITOLLER, 2011). É paradoxal que um movimento de reforma educacional que se propõe a beneficiar todos os estudantes seja implementado apenas com certos grupos. Acadêmicos e defensores da comunidade de deficiências de baixa prevalência produziram a maior parte do trabalho inicial para justificar a

Práxis Educativa, Ponta Grossa, v. 14, n. 3, p. 804-831, set./dez. 2019 Disponível em: <http://www.revistas2.uepg.br/index.php/praxiseducativa> 
inclusão nos EUA (ex., KUNC, 1992; SAILOR, 1991; SAILOR; GEE; KARASOFF, 1993). Estudiosos de deficiências de baixa incidência também produziram uma quantidade razoável de pesquisa qualitativa e de um único tema na área da educação inclusiva (EVANS et al., 1992; GIANGRECO et al., 1993; HUNT; FARRON-DAVIS, 1992; KOZLESKI; JACKSON, 1993; KURTH; MASTERGEORGE, 2012; SCHNORR, 1990; STAUB et al., 1994). No entanto, a maioria dos estudos sobre educação inclusiva publicados nos últimos 15 anos focalizou em alunos com alta prevalência de incapacidades (BULGREN et al., 2006; KLINGNER; VAUGHN, 1999; McLESKEY et al., 2012). A partir de 2005, os pesquisadores mudaram a atenção de como apoiar os alunos individualmente para organizar as escolas de forma a auxiliar uma variedade de serviços (ZUMETA, 2014). Esses projetos organizacionais para escolas destinam-se a ajudar os profissionais e os gestores escolares a se prepararem, prevenirem e apoiarem a movimentação de alunos das salas de aula para serviços de apoio mais intensivos. $\mathrm{Na}$ última reautorização do Elementary and Secondary Education Act [ESEA] - Lei de Educação Elementar e Secundária, promulgado em 2015, o Every Student Succeeds Act (Lei Todos os Estudantes Bem-sucedidos) incentiva os estados e seus distritos escolares a desenvolver abordagens organizacionais para a provisão de serviços e apoios educacionais adicionais. A ênfase continuada em categorias de alta prevalência pode refletir no fato de que estudantes com essas deficiências constituem a maioria da população da Educação Especial, que tem maior probabilidade de ser colocada no ensino geral e/ou que mais financiamento de pesquisa está disponível para desenvolver conhecimento de conteúdo em tópicos acadêmicos, como matemática, ciências e leitura.

\section{Local versus sistemas: o que conta como educação inclusiva?}

Documentamos anteriormente que a maior parte das pesquisas em educação inclusiva dos EUA tem duas unidades de análise, a saber: escolas ou salas de aula (ARTILES et al., 2006). A pesquisa anterior tendia a não ter especificidade em termos das categorias de deficiência representadas nesses estudos e, igualmente importante, muitos pesquisadores não conseguiram documentar a medição dos resultados. A pesquisa em sala de aula de educação inclusiva, por sua vez, apresentou limitações semelhantes, embora, em alguns casos, os relatórios incluíssem mais informações sobre as deficiências dos estudantes e as medições de resultados proximais. A pesquisa em sala de aula não tinha especificidade em torno dos fundamentos teóricos da noção de aprendizagem usada nessas investigações. Uma falha notável das investigações nessas duas vertentes de pesquisa é a incapacidade de examinar interseções nas identidades dos estudantes (por exemplo, raça, classe social, linguagem ou gênero) e sua potencial força mediadora em medidas de desenvolvimento ou aprendizagem (ARTILES et al., 2006).

Essas tendências na base de conhecimento empírica sugerem que a educação inclusiva parece ter se tornado a mais recente marca da educação especial (ARTILES; KOZLESKI; GONZALEZ, 2011; SKRTIC, 1991). Além disso, era comum na literatura de inclusão encontrar uma ênfase na colocação na educação regular. Nesse ponto, é importante notar que a noção de educação inclusiva evoluiu a partir de reformas anteriores que foram identificadas com termos como mainstreaming 5 , que evoluíram para a iniciativa de educação regular e, eventualmente, foram identificadas como integração e, finalmente, inclusão (plena). A próxima interação, a ideia ambiciosa de reformar sistemas educacionais inteiros, tornou-se uma preocupação com a localização física dos programas. A principal tarefa da educação inclusiva continua a girar em torno de mover os alunos de um tipo de espaço para outro. Erevelles (2011b) chegou ao ponto

\footnotetext{
${ }^{5}$ Nota de tradução: o vocábulo Mainstreaming significa aquilo que é normal, aceito pela maioria das pessoas. Pode, assim, ser traduzido como tradicional, convencional, generalizado.
}

Práxis Educativa, Ponta Grossa, v. 14, n. 3, p. 804-831, set./dez. 2019 Disponível em: < http://www.revistas2.uepg.br/index.php/praxiseducativa> 
de concluir que o principal impulso da inclusão se torna a mudança de alunos no tabuleiro educacional - um ato que simula tornar esses alunos "menos intrusos" em vez de tornar as escolas mais inclusivas (EREVELLES, 2011b, p. 2158).

Por exemplo, uma cuidadosa revisão bibliográfica de estudos sobre educação inclusiva no Journal of Special Education começa com a afirmação: "Full inclusion, in which students with disabilities are full-time members in general education classrooms, is a recognized, and increasingly common, educational practice" (HUNT; GOETZ, 1997, p. 3). Os autores examinaram a literatura existente sobre as percepções dos pais, as práticas de sala de aula e da escola, despesas relacionadas, desempenho escolar e relações sociais entre alunos com e sem deficiências. Apenas artigos de pesquisa que examinaram onde os alunos com necessidades mais significativas foram alocados e atendidos foram incluídos na análise. No entanto, como Skrtic, Sailor e Gee (1996) sugerem, as noções de rupturas fundamentais para os sistemas educacionais altamente burocratizados da segunda metade do século 20 fundamentam a educação inclusiva. Em vez de uma conversa sobre quais alunos excluídos da sala de aula poderiam ter acesso, a educação inclusiva parecia sinalizar uma nova lógica sobre o babitus da educação. Ou seja, a educação inclusiva exigiu transformações na organização e na estrutura das escolas e dos sistemas escolares, reformas pedagógicas que espelharam novos conhecimentos sobre como a aprendizagem emerge e a reforma institucional em que associados e voz servem como impulso para a concepção e a adequação de serviços às necessidades e aos contextos dos indivíduos e suas famílias (SKRTIC; SAILOR; GEE, 1996).

Apesar dos pedidos para entender as mudanças fundamentais que a educação inclusiva exigia, a maior parte da pesquisa dos EUA permaneceu atarefada em examinar os efeitos das atividades que ocorriam dentro das escolas existentes, em lugares específicos. A evidência tem sido mista quanto às maneiras pelas quais a participação dos alunos produziu resultados específicos, embora a falta de especificidade (ex.: sobre métricas de amostragem e resultado) complica as determinações sobre o impacto diferencial dos programas (ARTILES et al., 2006). Enquanto há muito a ser aprendido em como, por exemplo, uma sala de aula pode ser projetada para otimizar o desenvolvimento da alfabetização de todos os alunos, ela levanta questões sobre onde a aprendizagem deve ocorrer, para quem e com que tipos de recursos. Além disso, o foco em um local específico, como a sala de aula, restringe o campo de análise de forma que as influências sobre a aquisição e o uso da alfabetização sejam percebidas apenas dentro dos limites da sala de aula. Por fim, embora haja evidências do impacto positivo de programas inclusivos nos alunos com deficiências em alguns domínios, não é raro encontrar alunos com deficiências que experimentaram desigualdades mais profundas. Essas desigualdades surgiram porque as mudanças curriculares não ocorreram, a equipe não foi preparada ou não recebeu apoio para trabalhar com esses alunos, e/ou as avaliações não capturaram adequadamente o potencial e o desempenho dos alunos (SAILOR, 2002).

\section{Os horizontes da mudança: de télos e resultados}

Nos EUA, a educação inclusiva tem avançado como uma reforma da educação especial, um mandato de política que é regulado e monitorado pelos governos, bem como um movimento social que é promovido por uma variedade de defensores e interesses. A maioria das pesquisas publicadas sobre o tema vem da educação especial ou da psicologia educacional (WAITOLLER; ARTILES, 2013). Pesquisadores voltados aos estudos das deficiências têm também envolvido a conversa por meio de pesquisa e teoria (EREVELLES, 2011b). No entanto, para os profissionais

${ }^{6}$ Tradução: A inclusão plena, em que os alunos com deficiência são membros em tempo integral nas salas de aula de educação regular, é uma prática educativa reconhecida e cada vez mais comum.

Práxis Educativa, Ponta Grossa, v. 14, n. 3, p. 804-831, set./dez. 2019 Disponível em: <http://www.revistas2.uepg.br/index.php/praxiseducativa $>$ 
que trabalham nas escolas diariamente, o termo "educação inclusiva" é provavelmente associado à educação especial. De fato, uma revisão da literatura e análise do estado da educação inclusiva em 11 países sugere que a educação inclusiva continua associada (pelo menos na mente de profissionais e de formuladores de políticas) à educação de crianças com deficiência (ARTILES; KOZLESKI; WAITOLLER, 2011).

Um dos desafios de criar salas de aula inclusivas dentro das burocracias compartimentadas das escolas e dos sistemas escolares é que criar a inclusão dentro da compartimentalização pode ser impossível. Assim, o enigma para os proponentes da educação inclusiva é por onde começar. A educação inclusiva de primeira geração permaneceu no nível do aluno e da sala de aula. Alguns praticantes da educação regular foram resistentes a adotar modelos inclusivos (KAVALE; FORNESS, 2000). Uma vez que os estudos ultrapassaram a noção de incluir certos indivíduos e seu valor, pesquisadores e profissionais enfrentaram lutas com a natureza do currículo, com conceituações de aprendizagem e desenvolvimento, com estruturas, rotinas e processos técnicos embutidos na educação escolar, bem como com tensões entre a educação para uma comunidade democrática e a escolarização como um investimento econômico para fins de globalização (WAITOLLER; KOZLESKI, 2015).

Uma tensão importante dentro deste estudo aborda não apenas o impacto da educação inclusiva em estudantes com deficiências, mas também em pares típicos (BUNCH; VALEO, 2004; OCHS et al., 2001). Um argumento que foi feito é que os estudantes típicos correm o risco de serem desfavorecidos em termos de progresso no currículo, porque os alunos com deficiência exigem muita atenção e retardam o progresso dos alunos típicos. Um estudo significativo, financiado pelo Departamento de Educação dos EUA, examinou os efeitos de atender às crianças com e sem deficiência nas mesmas salas de aula. Em um projeto de pesquisa experimental, pesquisadores descobriram que os alunos sem deficiências têm um desempenho igual ou até mesmo superior em salas de aula em que alunos com diferentes habilidades e deficiências aprendem juntos. Korenich e Salisbury concluíram o relatório final de seu estudo em 2006, que reflete as pesquisas de Hanuschek, Kain e Rivkin (2002) e Huber, Rosenfeld e Fiorello (2001). Esses pesquisadores concluíram que trazer os alunos com habilidades e histórias diferentes não prejudica um grupo em benefício de outro, tendo em conta livros e materiais apropriados exigidos pelo currículo. Por outro lado, um estudo recente conduzido com um conjunto de dados representativos nacionalmente em larga escala sugere que ter colegas com deficiência na sala de aula tem um efeito sobre os resultados não cognitivos (por exemplo, comportamentos problemáticos, habilidades sociais) que foram moderados por fatores individuais e contextuais (GOTTFRIED, 2014).

A pesquisa sobre educação inclusiva da segunda geração, iniciada no início dos anos 2000, examinou estratégias de mudança nos níveis local, distrital e estadual (SKRTIC; SAYLOR; GEE, 2005). Entretanto, noções de educação inclusiva pareciam estar presas a uma conceituação de educação inclusiva como um avanço de novas estruturas de ensino para atender às necessidades das crianças com deficiência. As tentativas de reformular a conversa para incluir todos os alunos marginalizados se depararam com noções amplamente aceitas de senso comum sobre a educação inclusiva como uma agenda de deficiência. Essas tendências levantaram questões sobre a identidade da educação inclusiva. A educação inclusiva deve desistir de suas ambições para beneficiar a todos os alunos? $\mathrm{O}$ objetivo final deve continuar sendo o acesso aos cenários educacionais? Dada a preocupante negligência das medições de resultados para avaliar o impacto da educação inclusiva na participação do programa estudantil (ARTILES et al., 2006), quais devem ser as métricas de resultado para esse movimento?

Práxis Educativa, Ponta Grossa, v. 14, n. 3, p. 804-831, set./dez. 2019 Disponível em: <http://www.revistas2.uepg.br/index.php/praxiseducativa> 


\section{Convergências e contradições das reformas: a educação inclusiva dos EUA no século XXI}

Uma tendência raramente reconhecida na literatura é que a trajetória da educação inclusiva nos EUA se cruzou com outras políticas e esforços de reforma (por exemplo, políticas disciplinares, ESEA, políticas linguísticas) e muitas dessas iniciativas para remediar desigualdades para vários grupos de estudantes. As trajetórias de inclusão e essas políticas/reformas nem sempre se cruzaram de forma tranquila. Quando essas interseções convergem em contextos locais, são forjados significados idiossincráticos de inclusão, que são aplicados a indivíduos ou grupos de estudantes. Além disso, devido a incompatibilidades ou desalinhamentos entre as políticas/reformas convergentes, os "efeitos torque" (ou torções) podem ser produzidos nas políticas implementadas que resultam em decisões de classificação para determinados indivíduos (por exemplo, um diagnóstico de deficiência) que supostamente se "beneficiarão" de programas inclusivos. Essas decisões alteram as identidades sociais e físicas do público-alvo (ou seja, os classificados) nessas políticas (BOWKER; STAR, 2002; TIMMERMANS, 1996), produzindo novos tipos humanos (HACKING, 2007). Como resultado, a natureza e o significado dessas políticas assim como as trajetórias dos indivíduos ou grupos sofrem reviravoltas que muitas vezes têm consequências não intencionais, como disparidades raciais nas taxas de identificação de deficiências (ARTILES, 2011) ou exclusão de alunos com deficiências a partir de práticas de responsabilização, como testes de desempenho (THURLOW; KOPRIVA, 2015). A seguir, uma ilustração sobre as complexidades inerentes a esses efeitos torque.

A política do ESEA 2001 (também conhecida como No Child Left Behind - NCLB) trouxe mudanças substanciais na regulamentação federal das práticas educacionais, particularmente com sua ênfase em fechar as lacunas de desempenho entre os subgrupos de estudantes em leitura, matemática e ciências. A NCLB concentrou-se em garantir a responsabilização dos resultados educacionais, proporcionando opções aos pais sobre programas educacionais, privilegiando práticas baseadas em evidências e favorecendo o controle local e a flexibilidade. A divulgação pública de resultados educacionais foi fundamental para essa política e esses dados foram desagregados por subgrupos raciais, socioeconômicos, linguísticos e de deficiência. Esperava-se que as escolas que não alcançassem o progresso anual adequado (PAA) melhorassem com a implementação de intervenções e reformas específicas; caso contrário, essas escolas poderiam ser fechadas e/ou seria dada aos pais a opção de transferir seus filhos para escolas que atendessem ao PAA.

Por sua vez, o Individuals with Disabilities Education Act (IDEA) também estipula que os estados estabeleçam

- and report progress on meeting - 'performance goals for students with disabilities $[S W D]$ that are consistent with the state's definition of AYP' ... This alignment was to enhance the effectiveness of the education of [students with disabilities] by establishing high expectations, ensuring access to the general education curriculum, and coordinating school improvement efforts at different levels, in particular those stipulated by the ESEA7?. (HARR-ROBINS et al., 2012, p. 2).

\footnotetext{
7 Tradução: [...] e relatem o progresso na realização - 'de metas de desempenho para alunos com deficiências que são consistentes com a definição do estado de PAA'.. Esse alinhamento foi para aumentar a eficácia da educação de [alunos com deficiência], estabelecendo altas expectativas, garantindo o acesso ao currículo geral de educação, e coordenando os esforços de melhoria da escola em diferentes níveis, em particular os estipulados pelo ESEA.
}

Práxis Educativa, Ponta Grossa, v. 14, n. 3, p. 804-831, set./dez. 2019 Disponível em: <http://www.revistas2.uepg.br/index.php/praxiseducativa> 
Promessas e trajetórias da Educação Inclusiva: notas críticas sobre pesquisas futuras...

Devemos observar, no entanto, que os dados de aproveitamento de alunos com deficiência nem sempre foram tratados da mesma maneira para fins de prestação de contas (DARLING-HAMMOND, 2007). Isso criou o incentivo perverso para diagnosticar estudantes com deficiência como um meio de excluí-los dos sistemas de responsabilização.

Apesar das melhores intenções dessas políticas, várias consequências injustas foram documentadas. Por exemplo, embora algumas lacunas de desempenho entre grupos tenham melhorado (com diferentes magnitudes), persistem lacunas substanciais. A National Assessment of Educational Progress (Avaliação Nacional do Progresso Educacional) informa que as pontuações de leitura em 2015 não mostraram nenhuma mudança significativa nas lacunas de pontuação de leitura entre dois grupos de comparação, brancos e hispânicos e brancos e afro-americanos (Nation's Report Card, 2015). Por causa da considerável segregação racial e socioeconômica das escolas do país, esses grupos minoritários estão presos em contextos com menos recursos materiais e humanos, nos quais baixas taxas de desempenho educacional estão emaranhadas com desigualdades estruturais em um ciclo de autoperpetuação. $O$ manuseio incorreto (e a fraude total) de práticas de teste e relatórios de evidências foram documentados em todo o território dos EUA (NICHOLS; BERLINER, 2007). Além disso, um número desproporcional de estudantes de minorias raciais é alocado em programas de educação especial (LOSEN; ORFIELD, 2002), aumentando a probabilidade de que eles ficarão mais atrás academicamente.

Duas outras políticas que abordam desigualdades e oportunidades educacionais relacionadas ganharam visibilidade substancial nos EUA nos últimos anos. Em primeiro lugar, os principais casos de violência escolar contribuíram para a aprovação de políticas de tolerância zero para garantir a segurança escolar, um ambiente de aprendizagem produtivo e um sistema eficaz de disciplina escolar. Infelizmente, as evidências disponíveis refletem um estado de coisas inquietante. Um relatório da American Psychological Association ([APA], 2008) concluiu que as políticas de tolerância zero falharam em abordar as questões de disciplina e segurança na escola:

Zero tolerance has not been shown to improve school climate or school safety. Its application in suspension and expulsion has not proven an effective means of improving student behavior. It has not resolved, and indeed may have exacerbated, minority overrepresentation in school punishments. Zero tolerance policies as applied appear to run counter to our best knowledge of child development ${ }^{8}$ ([APA], 2008, p. $860)$.

Devemos também notar que a evidência disponível não apoia o argumento da pobreza estudantil, uma explicação comum para as disparidades raciais na disciplina. Para esclarecer: "when the relationship of socio-economic status to disproportionality in discipline has been explored directly, race continues to make a significant contribution ... independent of socioeconomic status"' (FABELLO et al. apud LOSEN, 2012, p. 12).

Em segundo lugar, o IDE $A$ exige que o diagnóstico de deficiência seja relatado pela raça do estudante. O sistema de monitoramento estabelecido inclui pelo menos dois recursos, como segue:

\footnotetext{
8 Tradução: A tolerância zero não foi mostrada para melhorar o ambiente escolar ou a segurança da escola. Sua aplicação em suspensão e expulsão não se mostrou um meio eficaz de melhorar o comportamento dos estudantes. Não resolveu, e de fato pode ter exacerbado, a representação excessiva das minorias nas punições escolares. Políticas de tolerância zero da forma que estão aplicadas parecem contrariar o nosso melhor conhecimento sobre desenvolvimento infantil.

9 Tradução: quando a relação do status socioeconômico com a desproporcionalidade na disciplina tem sido explorada diretamente, a raça continua a dar uma contribuição significativa ... independentemente do status socioeconômico.
}

Práxis Educativa, Ponta Grossa, v. 14, n. 3, p. 804-831, set./dez. 2019 Disponível em: <http://www.revistas2.uepg.br/index.php/praxiseducativa> 
First, Section 616 makes "disproportionate representation of racial and ethnic groups in special education ... . to the extent the representation is the result of inappropriate identification" a monitoring priority area and the primary source for states to report to the Secretary and to the public under Indicators 9 and 10. Second, Section 618 requires that each state collects and analyzes data to determine if "significant disproportionality based on race and ethnicity is occurring in the state and the [LEAs] of the State" with respect to identification, placement and discipline, and if so, these LEAs must spend $15 \%$ of their Part B funds on coordinated early intervening services ${ }^{10}$. (ALBRECHT et al., 2012, p. 16-17).

Essa política não exige o monitoramento desse problema para os alunos ingleses e não estabeleceu um limite para a desproporcionalidade. Assim, existe uma variabilidade substancial nas pontuações de corte que os estados exigem para iniciar ações corretivas (SULLIVAN; KOZLESKI, 2009). A maioria dos estados exige que os estudantes de minorias raciais tenham, pelo menos, entre duas a três vezes mais probabilidade de serem colocados em educação especial do que suas contrapartes para lançar autoavaliações distritais ou auditorias de agências de ensino estaduais. Alguns estados exigem que os padrões de desproporcionalidade sejam documentados dois ou três anos consecutivos antes que as respostas do estado sejam acionadas (ARTILES, 2011). Esse estado de coisas reflete a natureza protéica da ideia de deficiência, ou o que Star e Griesemer (1989) chamaram de "boundary objects"" - objetos limites. Assim, a noção de deficiência muda de definições científicas para definições federais, para a operacionalização do estado do construto, e é apropriado e contextualizado no âmbito da escola local de acordo com as circunstâncias únicas do trabalho e da vida pessoal dos profissionais (ARTILES, 2011). Esse fenômeno pode ser caracterizado como "alinhamento categórico" (EPSTEIN, 2007), no qual as definições científicas, administrativas e socioculturais da deficiência são laminadas como se tivessem o mesmo significado.

O "alinhamento categórico" da deficiência (ARTILES, 2011), que é forjado em escalas (de macro a micro níveis) de sistemas educacionais à medida que os procedimentos de monitoramento de políticas são atuados tem importantes implicações de equidade para grupos de estudantes. Especificamente, apesar do potencial da política de monitoramento para remediar desigualdades na educação especial, essas estratégias de jogo são profundamente problemáticas para estudantes de minorias raciais e linguísticas que já enfrentam barreiras históricas avassaladoras em relação às oportunidades educacionais (CAVENDISH; ARTILES; HARRY, 2014). Esse é particularmente o caso se considerarmos as implicações negativas associadas à colocação da educação especial. O recente relatório da Equity and Excellence Commission (U.S. Department of Education, 2013) resumiu alguns:

\footnotetext{
10 Tradução: Primeiro, a Seção 616 faz "representação desproporcional de grupos raciais e étnicos na educação especial... na medida em que a representação é o resultado de identificação inadequada" uma área prioritária de monitoramento e a principal fonte de informação dos estados para a Secretaria e para o público nos Indicadores 9 e 10. Segundo, a Seção 618 exige que cada estado colete e analise dados para determinar se "uma desproporcionalidade significativa baseada em raça e etnia está ocorrendo no estado e nas [LEAs] do Estado" com relação à identificação, colocação e disciplina, e se assim for, essas LEAs devem gastar 15\% de seus fundos da Parte B em serviços coordenados de intervenção precoce.

11 Objetos limites possuem diferentes significados em diferentes mundos sociais, mas sua estrutura é comum o suficiente para mais de um mundo para torná-los reconhecíveis, um meio de tradução. A criação e o gerenciamento de objetos limites é um processo-chave no desenvolvimento e na manutenção da coerência entre mundos sociais que se cruzam (STAR; GRIESEMER, 1989, p. 393).
}

Práxis Educativa, Ponta Grossa, v. 14, n. 3, p. 804-831, set./dez. 2019 Disponível em: <http://www.revistas2.uepg.br/index.php/praxiseducativa> 
Promessas e trajetórias da Educação Inclusiva: notas críticas sobre pesquisas futuras...

[Students with disabilities] frequently have had special problems gaining full access to schools' general education curriculum; are often placed in separate classrooms for more than $20 \%$ of the school day; are suspended at disproportionately high rates; often lack teachers who are dual-certified in a content area; and do not receive appropriate instructional differentiation aligned with their disabilities ${ }^{12}$ (U.S. Department of Education, 2013, p. 14).

Adicionado a essas adversidades estão outras tendências preocupantes de longa data. Por exemplo, sabemos que minorias raciais e linguísticas, como estudantes com deficiências, desempenham um nível significativamente inferior em avaliações acadêmicas padronizadas do que suas contrapartes (LEE; REEVES, 2012). Eles também exibem maior abandono e menores taxas de graduação (U.S. Department of Education, 2013).

Para concluir, as minorias (raciais e linguísticas) continuam a experimentar desigualdades educacionais substanciais, embora as reformas tenham como objetivo colmatar as lacunas de desempenho, tornar as escolas mais responsáveis e mais seguras e produzir diagnósticos mais equitativos sobre deficiências. Considerando que sanções disciplinares e rótulos de deficiência são adicionados às identidades desses grupos em números desproporcionais, suas trajetórias em direção às desigualdades são ainda mais agravadas. O efeito combinado dessas desigualdades perpetua o que tem sido descrito como "discriminação de segunda geração" - como, por exemplo, estruturas, políticas e práticas que limitam o acesso a programas, práticas, recursos humanos/materiais e conhecimento de alto valor dentro das instituições (por exemplo, rastreamento do currículo), reproduzindo condições não equitativas (MEIER; STEWART; ENGLAND, 1989; NOGUERA, 2007).

Felizmente, vários esforços estão sendo realizados para remediar injustiças. Por outro lado, efeitos torque e consequências não intencionais de equidade são produzidos nas interseções dessas reparações. De fato, as evidências sugerem que as desigualdades podem se aprofundar para os próprios estudantes alvo dessas reformas, quando mandatos e políticas convergem em configurações locais - ex.: embora haja maiores demandas de responsabilização para todos os estudantes, muitos dos que vivem sob a violência das desigualdades estruturais históricas não estão obtendo os recursos materiais e humanos mais básicos para atender a essas exigências políticas. Enquanto isso, instituições educacionais podem misturar grupos não dominantes em um labirinto de identidades para evitar o impacto de burocracias de monitoramento e conformidade. Assim, muitos aprendizes não dominantes tornam-se infratores disciplinares crônicos e, eventualmente, ingressam nos sistemas de justiça juvenil/correcional ou recebem rótulos de incapacidade. Transferir identidades de estudantes dessa maneira permite que os sistemas educacionais evitem o panóptico da responsabilidade, possibilitando, assim, que eles se mantenham longe das autoavaliações de conformidade ou das auditorias estaduais, enquanto a discriminação de segunda geração permanece incólume.

Esse é o contexto no qual os programas de educação inclusiva estão sendo implementados; essas são as trajetórias de origem de muitos dos alunos que entram nos programas inclusivos. No entanto, há pouca atenção a essas influências contextuais e suas implicações na construção de ambientes de educação inclusiva, nem no corpo de pesquisa que visa estudar e avançar o conhecimento em e sobre a educação inclusiva. Dadas as trajetórias

\footnotetext{
12 Tradução: [Alunos com deficiências] frequentemente tiveram problemas especiais, obtendo acesso total ao currículo escolar geral das escolas; são frequentemente colocados em salas de aula separadas por mais de $20 \%$ do dia escolar; estão suspensos a taxas desproporcionalmente altas; muitas vezes faltam professores com certificação dupla em uma área de conteúdo; e não recebem diferenciação instrucional apropriada alinhada às suas deficiências (U.S. Department of Education, 2013, p. 14).
}

Práxis Educativa, Ponta Grossa, v. 14, n. 3, p. 804-831, set./dez. 2019 Disponível em: <http://www.revistas2.uepg.br/index.php/praxiseducativa> 
históricas, tendências de pesquisa, lacunas e paradoxos na literatura sobre educação inclusiva, finalizamos este artigo com notas para uma futura agenda de pesquisa.

\section{Reimaginando futuros possíveis: notas para uma agenda de pesquisa}

$\mathrm{Na}$ seção que segue, refletimos sobre o potencial de alianças estratégicas para alavancar a busca pela educação inclusiva, discutir as implicações de entendimentos mais fluidos de capacidade e incapacidade e defender o estudo dos processos e dos resultados da educação inclusiva.

\section{Além das deficiências: as possibilidades e os desafios das alianças estratégicas}

Alguns analistas caracterizariam a educação inclusiva como um importante contribuinte para o movimento pelos direitos das pessoas com deficiência. De fato, alinhada a vitórias precedentes na evolução histórica desse movimento (por exemplo, IDEA; Americans with Disabilities $\left.A c t^{3}[\mathrm{ADA}]\right)$, a educação inclusiva foi amplamente justificada pelo argumento de direitos civis. Historicamente, tem havido sinergias para forjar ganhos de direito civil entre diferentes grupos minoritários. O movimento pelos direitos das pessoas com deficiência, por exemplo, se beneficiou das lições, das estratégias e das vitórias das lutas afro-americanas pelos direitos civis. Reconheceu-se que a adoção de uma identidade coletiva como deficiente sob um modelo de grupo minoritário, juntamente a demandas por direitos legais, produziu a "base teórica" para a ADA (HAHN, 2000).

Por outro lado, o movimento pelos direitos das pessoas com deficiência recebeu muito menos atenção em áreas que tradicionalmente estudaram os movimentos sociais, como a sociologia e os estudos jurídicos críticos (GUSTAFSON, 2006). Os estudiosos da LatCrit, por exemplo, reconheceram que o engajamento de comunidades e questões sobre deficiências tem sido ad hoc na melhor das hipóteses (IGLESIAS; VALDES, 2001, p. 1293). Gustafson (2006, p. 1022) também afirmou que os estudos legais parecem ficar aquém dos escritos em estudos de deficiência ao analisar a construção legal da deficiência. Essa falta de fertilização cruzada interdisciplinar contradiz o compromisso dos movimentos sociais com projetos coletivos de justiça social para todos os grupos marginalizados. É lamentável que os movimentos sociais de diferentes grupos marginalizados não tenham se engajado em análises mais complexas de eixos de opressão que incluam deficiência. Isso é particularmente lamentável para o movimento de educação inclusiva, considerando que, em sua versão expansiva, está supostamente preocupado com todas as formas de diferença, e em sua interação estreita, enfoca a deficiência, que é uma categoria permeável que, como explicamos em uma seção anterior, regularmente percorre raça, gênero, linguagem, orientação sexual, classe social e nacionalidade.

Alianças estratégicas e coalizões entre o movimento de educação inclusiva e outros movimentos sociais poderiam contribuir para vários objetivos cruciais. Por exemplo, essas alianças poderiam pressionar por políticas mais responsivas e maior financiamento de pesquisa sobre as interseções de deficiência com outros marcadores de diferença, como raça, gênero, linguagem e classe social. Da mesma forma, alianças estratégicas poderiam contribuir para o refinamento de métricas generativas sobre o impacto de tais movimentos. Embora não haja consenso sobre um conjunto de indicadores de sucesso, as medidas comuns incluem integração, avanço econômico e vitórias simbólicas conquistadas em processos judiciais (GUSTAFSON, 2006). As pessoas com deficiência não se saem bem nesses índices, e o quadro é mais sombrio

\footnotetext{
${ }^{13}$ Tradução possível: Lei dos Americanos com Deficiência.
} 
Promessas e trajetórias da Educação Inclusiva: notas críticas sobre pesquisas futuras...

quando examinamos as evidências nas interseções de raça, de gênero, de classe social e de deficiência (ARTILES, 2013).

O que a ênfase da educação inclusiva em oportunidades educacionais acrescentaria à análise do impacto de um movimento social? Devido às persistentes complicações de raça, de gênero e de deficiência, como alianças estratégicas e coalizões com grupos raciais e de gênero podem promover a missão e os objetivos do movimento de educação inclusiva, particularmente quando pressionamos a questão sobre o que Susan Silbey (2005, p. 323) descreveu como "Consciência legal?" - ex.: "Por que as pessoas concordam com um sistema legal que, apesar de suas promessas de igualdade de tratamento, reproduz sistematicamente a desigualdade?". Essas são de fato perguntas urgentes que os futuros estudos de inclusão devem enfrentar. Curiosamente, os esforços para construir alianças entre os direitos das mulheres, os direitos dos deficientes, a justiça reprodutiva e os ativistas da justiça racial que defendem as prioridades políticas estratégicas mostraram resultados animadores (ROBERTS; JESUDASON, 2013).

Não obstante a promessa de coalizões, devemos observar uma ressalva. Alianças estratégicas não acontecem no vácuo. Os movimentos sociais trabalham com categorias de diferenças que têm significados históricos culturais e bagagem. Esse fato pode complicar e até minar esses esforços. Há evidências, por exemplo, de que indivíduos brancos com deficiência relutam em se engajar em um discurso sobre os direitos das pessoas com deficiência ao refletirem sobre tratamentos injustos passados ou ao articularem soluções para experiências discriminatórias (ENGEL; MUNGER, 2003). A relutância desses indivíduos em invocar um discurso de direitos resultou de sua fala de igualdade de direitos com o estigma da raça, e o uso de tal retórica os identificaria com um grupo com o qual eles não gostariam de construir alianças. Esse é um caso interessante de direitos (supostamente universais) que criam resistência ao progresso nas agendas de direitos civis (GUSTAFSON, 2006). Há uma necessidade premente de investigações adicionais sobre esse fenômeno de "resistência", uma vez que afeta grupos vulneráveis, como os meninos afro-americanos com deficiências, já que eles se encontram desproporcionalmente representados em algumas categorias de deficiências.

Devemos também notar que a globalização e as diásporas de múltiplos grupos em todo o mundo estão criando o que Ash (2012) descreveu como "sociedades paralelas" ou "isolamento subsidiado" dentro das nações desenvolvidas que, por sua vez, estão aprofundando desigualdades para grupos marginalizados e poderia colidir com esse fenômeno de "resistência" entre categorias de diferenças. Os esforços da educação inclusiva para construir coalizões com outros movimentos sociais deveriam estar atentos a esses desafios em potencial, e um trabalho considerável seria necessário para examinar possíveis vieses, percepções, estereótipos e preconceitos sobre deficiências entre outros movimentos sociais. Com base em Gustafson (2006, p. 1020), as alianças estratégicas da educação inclusiva com outros movimentos sociais precisarão repousar em análises cuidadosas da interdependência de vários discursos de direitos.

\section{Interseções nos estados fluidos de deficiência: um novo programa de pesquisa}

A educação inclusiva não aproveitou os estudos sobre a fluidez da deficiência que foi produzida em estudos sobre deficiência, estudos jurídicos, ciências sociais e humanidades. O conceito de deficiência como uma "categoria fluida e expansiva" (GUSTAFSON, 2006, p. 1023) foi formulado em pelo menos dois aspectos importantes. Em primeiro lugar, a deficiência tem sido teorizada como uma experiência humana universal, porque as pessoas a habitam de maneiras diferentes e em pontos diversos no curso de suas vidas. Assim, a deficiência é permeável à medida que os indivíduos entram e (às vezes) saem dela ao longo do tempo (CROSSLEY, 1999). Em segundo lugar, as identidades de deficiência transformam-se de um contexto para outro,

Práxis Educativa, Ponta Grossa, v. 14, n. 3, p. 804-831, set./dez. 2019 Disponível em: <http://www.revistas2.uepg.br/index.php/praxiseducativa> 
dependendo de como os indivíduos as experimentam, de como as pessoas em contextos discrepantes se envolvem com elas e de como as condições e as práticas institucionais medeiam as possibilidades, as restrições e/ou as consequências ligadas às deficiências (VARENNE; McDERMOTT, 1999). De certa forma, essa dimensão fluida da deficiência requer atenção analítica à governamentalidade (isto é, as formas pelas quais os discursos e as práticas institucionais "estruturam o campo de ação possível dos outros") (FOUCAULT, 1986) de identidades consideradas fora do campo do "normal" e como essa governamentalidade é desempenhada em certas práticas cotidianas na escola e além dela.

A fluidez da deficiência tem implicações importantes para a pesquisa sobre educação inclusiva. Talvez a consequência mais óbvia seja a necessidade de usar uma perspectiva situada no estudo da deficiência. Se as contingências contextuais são críticas para entender como a deficiência adquire significados diferentes, provoca respostas díspares e é mediada diferencialmente por forças institucionais, os pesquisadores serão obrigados a documentar a natureza situada da deficiência, e os aspectos relevantes pertinentes aos propósitos de suas investigações (por exemplo, desenvolvimento infantil ou aprendizagem). Desse modo, a educação inclusiva deve passar de uma preocupação com a política da identidade para entender a "política do engajamento" (NARAIAN, 2013), para ver a deficiência como baseada não em "ser", mas em 'tornar-se" (EREVELLES, 2011a). Em outras palavras, a futura pesquisa em educação inclusiva deve ir além do exame dos padrões de colocação e dos efeitos dos currículos e das intervenções nos resultados estáticos (por exemplo, notas de desempenho, frequência de comportamentos disruptivos). Em vez disso, a pesquisa precisa levar em conta os entendimentos orientados pelo processo de como as categorias mudam e os alunos experienciam programas dentro dos contextos escolares locais. Por exemplo, os pesquisadores podem estudar como as necessidades de linguagem e saúde mental dos estudantes de língua inglesa se dissolvem em registros institucionais depois que um diagnóstico de deficiência de aprendizagem é atribuído. Outro estudo pode examinar como os recursos de alfabetização dos estudantes de língua inglesa como primeira língua (L1) são usados (ou ignorados) durante a instrução. A atenção simultânea a uma combinação de fatores locais e estruturais (por exemplo, falta de conhecimento dos professores, requisitos de políticas para ignorar a L1, financiamento escasso para contratar orientadores bilíngues) pode ajudar a esclarecer como essas práticas instrucionais emergem e com que propósito.

Tal pesquisa precisa explorar as trajetórias das condições incapacitantes na biografia de uma pessoa (por exemplo, é uma condição temporária? Ela estava presente no nascimento?), e envolver-se com os "silêncios ativos" (EREVELLES, 2011b) que são revelados nas interseções de deficiência com raça, classe social, linguagem, etnia, gênero e assim por diante. A amostragem, portanto, exigirá uma abordagem mais refinada que examine a diversidade dentro da população e as condições institucionais e contextuais. Tal pesquisa marcaria um avanço importante na educação inclusiva, pois os pesquisadores documentaram durante décadas limitações substanciais nas estratégias de relato de amostra que têm implicações cruciais para a agregação dos resultados de pesquisa. Por exemplo, problemas foram observados na amostragem de alunos com dificuldades de aprendizagem (ARTILES; TRENT; KUAN, 1997; KEOGH et al., 1982; TRENT et al., 2014; VASQUEZ et al., 2011), estudos sobre a voz do estudante (GONZALEZ; HERNANDEZ-SACA; ARTILES, 2013), e estudantes de língua inglesa (ARTILES; KLINGNER, 2006; RAGAN; LESAUX, 2006).

Além disso, a fluidez da deficiência requer uma perspectiva comparativa em questões e projetos de pesquisa. Especificamente, espera-se que os pesquisadores produzam conhecimentos que contrastem o significado e as consequências das deficiências em contextos institucionais e situações sociais. Isso significa, por exemplo, que a pesquisa mudaria de documentar como 
Promessas e trajetórias da Educação Inclusiva: notas críticas sobre pesquisas futuras...

alunos com dificuldades de aprendizagem inseridos em programas inclusivos adquirem habilidades básicas de alfabetização para detalhar as maneiras pelas quais os alunos com dificuldades de aprendizagem usam ferramentas de alfabetização em contextos (por exemplo, tarefas de redação em sala de aula, fazer compras, jogar videogames com amigos ou irmãos em casa). Além disso, pesquisadores explorarão as finalidades para as quais os alunos com dificuldades de aprendizagem (a) usam ferramentas de alfabetização, (b) identificam quais ferramentas são mais impactantes pela configuração, e (c) quais consequências esses achados têm para a definição de competência na alfabetização de aprendizes com dificuldades de aprendizagem. Os estudos também podem examinar o uso de ferramentas em uma variedade de "tipos" de alunos, nos quais os próprios estudantes são vistos de maneiras complexas. Assim, os participantes do estudo podem incluir descrições de si mesmos que revelem as condições socioculturais em que vivem, como aprendem, as línguas que usam (e para quais objetivos) e suas oportunidades históricas e atuais de aprender. Organizada de forma a reconhecer a natureza multifacetada dos alunos, a pesquisa sobre educação inclusiva pode ajudar os educadores a reexaminar a maneira como pensam sobre seus alunos e como eles se organizam para atendê-los. Por exemplo, noções convencionais sobre o que estudantes com várias capacidades intelectuais são capazes de aprender e realizar precisam ser recalibradas. Cada vez mais, os alunos com deficiências de baixa prevalência são capazes de se envolver e se beneficiar do aprendizado acadêmico (SAUNDERS et al., 2013). Como isso acontece, sob quais condições e quais são as implicações para a organização dos contextos de aprendizagem, permanece completamente incompreendido.

\section{Complexidades da inclusão: processos de documentação e resultados}

Explicamos anteriormente que a educação inclusiva é fundamentada em um discurso de direitos que visa expandir o acesso a recursos valiosos (por exemplo, currículo de educação regular, interações sociais com diversos alunos). Assim, foram criados sistemas para monitorar a proporção de alunos com deficiências que são educados em diferentes porções do cotidiano escolar em salas de aula de educação regular como um índice de inclusão. A ênfase nos direitos e no acesso é crucial, pois constitui a pedra angular dos projetos de justiça liberal na América contemporânea (RAWLS, 2001). No entanto, é necessário que a educação inclusiva amplie sua agenda de justiça para o que acontece após o que é indexado como inclusão (ou seja, acesso) seja alcançado (ARTILES, 2012). Quando a educação inclusiva define estreitamente o seu objetivo final como acesso a ambientes físicos, devemos ser lembrados de que nossa obrigação ética deve ser perguntar o que acontece após a inclusão? - ou seja, deveríamos examinar a atuação dos direitos conquistados com dificuldade após os estudantes passarem pelas portas das salas de aula de educação regular (ARTILES, 2012).

Embora exista um conjunto de trabalhos sobre as características das escolas envolvidas na educação inclusiva, quase não há atenção aos dilemas/às tensões/às contradições de equidade que surgem da implementação da inclusão (para exceções ver ARTILES; KOZLESKI; GONZALEZ, 2011; KOZLESKI et al., 2013, KOZLESKI; SMITH, 2009). Essa perspectiva está relacionada ao que Gustafson (2006) descreveu como "direitos em ação", isto é, os direitos podem se tornar ativos no dia a dia, mesmo quando os indivíduos não escolhem afirmá-los (ENGEL; MUNGER, 2003, p. 11). Não devemos supor que os direitos sejam entidades inertes esculpidas em estatutos e políticas. Em vez disso, seguindo os estudiosos da lei e da sociedade, a educação inclusiva precisa examinar seus direitos em ação nas interseções das (a) interpretações formais de direitos das instituições, (b) os esforços dos indivíduos para convocar direitos, e (c) a cultura da sociedade em geral (GUSTAFSON, 2006). Como apontamos em uma seção anterior, a educação inclusiva coexiste com uma miríade de reformas e políticas, algumas das quais visam

Práxis Educativa, Ponta Grossa, v. 14, n. 3, p. 804-831, set./dez. 2019 Disponível em: <http://www.revistas2.uepg.br/index.php/praxiseducativa> 
agendas de equidade e concedem direitos alternativos. Essas reformas sobrepostas e seus direitos associados podem ter consequências não intencionais que poderiam aprofundar as desigualdades que pretendiam antes de tudo resolver.

As desigualdades que surgem nos sistemas de educação inclusiva podem ser identificadas como uma nova forma de discriminação que foi denominada "exclusões inclusivas" ou “discriminação pela inclusão" (CARBADO; FISK; GULATI, 2008). Uma perspectiva de direitos em ação permitirá que os pesquisadores de inclusão examinem as atuações cotidianas de políticas e práticas inclusivas. Esses processos de implementação estão carregados de premissas institucionais e se cruzam com as práticas associadas a outros mandatos de capital. Essa manivela das práticas torna-se visível nos processos interpessoais que moldam vantagens para alguns e desvantagens para outros (CARBADO; FISK; GULATI, 2008).

Consideremos, por exemplo, três conjuntos de esforços que abordam oportunidades educacionais, a saber: educação inclusiva, monitoramento de requisitos para reduzir a racialização de deficiências e políticas linguísticas para apoiar alunos de inglês. A educação inclusiva nos EUA tipicamente monitora se alunos com necessidades especiais estão sendo educados em escolas comuns e salas de aula de educação regular por uma proporção considerável do dia escolar. $\mathrm{O}$ trabalho de inclusão, no entanto, pode não estar monitorando se os subgrupos de alunos (por exemplo, alunos de inglês, minorias raciais) estão se beneficiando igualmente dessas políticas e dessas práticas.

Por outro lado, os alunos de inglês experimentaram ao longo do tempo um esforço de assimilação por meio de políticas como a educação bilíngue, na qual a prova de sucesso é a aquisição do inglês (em oposição à obtenção do bilinguismo). Já se argumentou que o racismo pode promover a assimilação, e um caso em questão são os alunos de inglês - isto é, as pessoas devem ser forçadas a desistir de algum aspecto de sua identidade - por exemplo, a linguagem para se adequar à sociedade americana dominante e suas instituições"? (CARBADO; FISK; GULATI, 2008, p. 13). Dado o foco assimilacionista dessas políticas de linguagem, não é de surpreender que uma medida de proficiência em inglês seja usada como critério de entrada e saída desse programa (RAGAN; LESAUX, 2006).

Uma consequência dessa prática é que o público de aprendizagem de língua inglesa é perenemente composto de alunos, pelo menos em algumas séries, com níveis mais baixos de proficiência linguística e desempenho acadêmico (FRY, 2007; U.S. Department of Education, 2013). Devido a essa prática, esse público pode ter uma probabilidade maior de ser diagnosticado com um rótulo de incapacidade, particularmente em estados que possuem sistemas mais fracos de suporte de linguagem (ARTILES; WAITOLLER; NEAL, 2011). De fato, evidências emergentes sugerem que aprendizes de língua inglesa são desproporcionalmente alocados em educação especial em algumas localidades e estados. Como as pressões para reduzir o número de alunos de língua inglesa nos sistemas escolares criam incentivos para os encaminhamentos desses alunos à educação especial, uma vez que os suportes de idiomas para esses aprendizes tendem a desaparecer quando esses alunos são diagnosticados com uma deficiência? Alunos de língua inglesa estão desproporcionalmente representados em certas categorias de deficiência? Como a interseção de uma segunda língua com deficiência dificultaria oportunidades educacionais inclusivas para certos grupos? Até que ponto os alunos de língua inglesa seriam invisíveis em programas de educação inclusiva? Estas são algumas das questões que não seriam abordadas se a atenção a uma perspectiva de direitos em ação estiver ausente.

Além disso, alguns estados podem estar engajados na "conformidade ritual" (SCHEID; SUCHMAN, 2001) com relação ao monitoramento dos requisitos sobre a desproporcionalidade racial na educação especial. Isto é, alguns distritos e/ou estados podem resistir aos requisitos da 
Promessas e trajetórias da Educação Inclusiva: notas críticas sobre pesquisas futuras...

política por uma série de razões (fiscais, técnicas, políticas); assim, cortar os escores de desproporcionalidade que desencadeiam ações corretivas e as determinações sobre a "identificação inadequada" de estudantes de minorias são mantidas a um mínimo (CAVENDISH; ARTILES; HARRY, 2014). No entanto, esses estados ou distritos podem fazer gestos de conformidade simbólica em relação à política, participando de relatórios e conduzindo autoavaliações sobre práticas de colocação. Dessa forma, os próprios profissionais que devem cuidar do desenvolvimento e do bem-estar dos estudantes podem se tornar executores involuntários de hierarquias de longa data (NARAIAN, 2013).

Uma pesquisa sobre a desproporcionalidade também revela que os alunos das minorias são alocados em ambientes mais segregados do que os seus colegas brancos com o mesmo diagnóstico de deficiência (SKIBA et al., 2008). No entanto, alguns estudiosos da educação inclusiva podem não perceber que mais estudantes não dominantes são destinados à educação especial (isto é, minorias raciais, alunos de língua inglesa) ou se tornam cientes do nível de restrição nas decisões de colocação em relação à raça de estudantes ou experiência linguística se uma postura de direitos em ação não for usada nesses esforços de reforma múltipla. Uma implicação crucial dessas reflexões, portanto, é que os pesquisadores devem contar com sistemas abrangentes de monitoramento e, de acordo com Gustafson (2006, p. 1022), procurar mudanças pós-atuação não apenas na experiência individual, mas também nas estruturas organizacionais, percepções individuais, cultura legal e identidade individual.

\section{Conclusão}

Apresentamos uma discussão crítica das ideias fundamentais que apoiam o movimento de educação inclusiva e as trajetórias históricas do trabalho realizado até o momento nos EUA. Nosso escopo é amplo e iniciamos a análise com uma discussão sobre limitações conceituais na definição de inclusão. Mostramos que a comunidade acadêmica produziu vários discursos sobre inclusão que dependem de suposições alternativas e enfatizam visões discrepantes de justiça. Argumentamos que essa cacofonia de pontos de vista não é necessariamente um problema, mas cria desafios para o alinhamento de múltiplas agendas de reforma educacional e a própria implementação da inclusão, que, por sua vez, repercute na construção de uma base de conhecimento de pesquisa sobre educação inclusiva. Concluímos que os estudiosos da inclusão não têm sido suficientemente sistemáticos ao examinar criticamente essas tendências conceituais e de implementação.

Além disso, resumimos a pesquisa produzida sobre esse tópico nos EUA. Descobrimos que a pesquisa sobre inclusão tende a se concentrar em escolas ou salas de aula inteiras e a atenção a esse tópico na literatura de pesquisa variou por um período de tempo. Também identificamos várias lacunas e paradoxos nesta pesquisa. Ademais, enfatizamos os contextos sociopolítico e técnico nos quais a inclusão é atuada nas escolas dos EUA do século XXI. A inclusão coexiste com várias outras reformas que compartilham um compromisso com as agendas de justiça. Semelhante à inclusão, essas reformas são fundamentadas em uma perspectiva de direitos e acesso à justiça. Sugerimos que a coexistência de múltiplas reformas que supostamente compartilham um propósito de justiça pode realmente criar rupturas e contradições entre esses projetos de mudança, ou como Timmermans (1996) descreveu, "efeitos torque" que têm consequências não apenas para os movimentos de reforma, mas também para as identidades dos alunos.

Nós desafiamos acadêmicos e profissionais de inclusão a refletir e refinar a identidade desse movimento. É uma teoria da educação, uma reforma da educação especial, outra exigência política para atender às necessidades de determinados grupos de estudantes ou um movimento

Práxis Educativa, Ponta Grossa, v. 14, n. 3, p. 804-831, set./dez. 2019 Disponível em: <http://www.revistas2.uepg.br/index.php/praxiseducativa> 
social? Estas não são opções mutuamente exclusivas, mas se algumas delas estiverem interrelacionadas de alguma forma, devemos especificar a natureza dessas conexões e suas implicações para a pesquisa, para a política e para a prática. Nós exploramos questões com amostras de estudo que enfatizam indivíduos com alta prevalência de deficiência e minimizam os múltiplos aspectos de suas experiências, incluindo a participação em comunidades específicas de prática, histórias de vida, interesses e oportunidades. E, finalmente, enfatizamos que a educação inclusiva, que se concentra no lugar como o principal índice de realização não leva em conta as atividades mais complexas de comunidades inclusivas que envolvem interação, associação, participação e reformação.

As discussões sobre o estado da educação inclusiva e suas limitações teóricas e metodológicas nos levaram a identificar várias áreas que o futuro acadêmico deveria engajar. Em primeiro lugar, exploramos a necessidade de buscar alianças estratégicas com outros movimentos que buscam agendas de inclusão. De fato, como outros movimentos que trabalham para e com grupos oprimidos, o movimento de educação inclusiva compartilha um compromisso com a justiça. Alianças com essas comunidades alavancariam recursos e fortaleceriam os recursos intelectuais e metodológicos da inclusão. Por outro lado, também advertimos que esses tipos de alianças não são construídos sem percalços, particularmente entre grupos que trabalham com comunidades marginalizadas, devido à bagagem política e histórica que certos marcadores de diferença (por exemplo, raça) têm no cerne de várias comunidades. Em segundo lugar, estudos de inclusão precisam assumir a ideia de interseccionalidade, pois as identidades dos alunos do século XXI incorporam formas multidimensionais de diferença. Esse fato também está relacionado à noção de deficiência como uma entidade fluida no sentido da permeabilidade desse construto isto é, as pessoas viajam dentro e fora da deficiência em diferentes pontos de suas vidas, e a deficiência é contingente aos contextos sociais em que os indivíduos se envolvem e participam com os outros em práticas institucionais. Essas complexidades desafiam os pesquisadores a produzir conhecimento sobre a deficiência e suas interseções com múltiplas identidades, usando uma lente analítica situada e com uma perspectiva êmica mais forte.

Uma mudança crítica nos futuros estudos de inclusão é a unidade de análise. Nós documentamos que a maioria dos estudos tinha foco na escola como um todo ou na sala de aula. No entanto, os conjuntos de dados são construídos e os resultados da pesquisa são relatados com $\mathrm{o}$ aluno individual em mente. Argumentamos que pesquisas futuras devem ser fundamentadas em uma unidade de análise que examine indivíduos inseridos em sistemas de atividades de múltiplas camadas. Isso fortalecerá a generalização das descobertas para que os estudos levem em consideração as condições institucionais nas quais os estudantes participam de sistemas inclusivos. Essa mudança também permitirá que os estudiosos vinculem sistematicamente macro e micro forças no estudo da inclusão.

Finalmente, sugerimos que estudos futuros voltados à educação inclusiva devem atentar para a complexidade e aos processos e aos resultados de implementação de documentos. Propusemos produzir novos estudos baseados na noção de "direitos em ação" para documentar como os direitos da educação inclusiva e as legitimidades são assumidos nas conjunturas de interpretação dessas instituições sobre esses direitos, como os indivíduos pleiteiam esses direitos, e a(s) cultura(s) das comunidades em geral. 


\section{Referências}

ALBRECHT, S. F. et al. Federal policy on disproportionality in special education: is it moving us forward? Journal of Disability Policy Studies, v. 23, n. 1, p. 14-25, 2012. DOI: http://dx.doi.org/10.1177/1044207311407917

AMERICAN PSYCHOLOGICAL ASSOCIATION (APA). Are zero tolerance policies effective in the schools?: an evidentiary review and recommendations. American Psychologist, v. 63, n. 9, p. 852-862, 2008. DOI: http://dx.doi.org/10.1037/0003-066X.63.9.852

ARTILES, A. J. Toward an interdisciplinary understanding of educational equity and difference: the case of the racialization of ability. Educational Researcher, v. 40, n. 9, p. 431-445, 2011. DOI: http://dx.doi.org/10.3102/0013189X11429391

ARTILES, A. J. After inclusion: notes on the future of a (transformative?) idea. Presentation made at the School of Education, University of Birmingham, Birmingham, 2012.

ARTILES, A. J. Untangling the racialization of disabilities: an intersectionality critique across disability models. Du Bois Review: Social Science Research on Race, v. 10, n. 2, p. 329-347, 2013. DOI: http://dx.doi.org/10.1017/s1742058x13000271

ARTILES, A. J. et al. Learning in inclusive education research: re-mediating theory and methods with a transformative agenda. Review of Research in Education, v. 30, n. 1, p. 65-108, 2006. DOI: http://dx.doi.org/10.3102/0091732X030001065

ARTILES, A. J.; DYSON, A. Inclusive education in the globalization age: the promise of comparative cultural historical analysis. In: MITCHELL, D. (Ed.). Contextualizing inclusive education. London: Routledge, 2005, p. 37-62.

ARTILES, A. J.; HARRIS-MURRI, N.; ROSTENBERG, D. Inclusion as social justice: critical notes on discourses, assumptions, and the road ahead. Theory into Practice, v. 45, n. 3, p. 260268, 2006. DOI: http://dx.doi.org/10.1207/s15430421tip4503 8

ARTILES, A. J.; KLINGNER, J. K. Forging a knowledge base on English language learners with special needs: theoretical, population, and technical issues. Teachers College Record, v. 108, n. 11, p. 2187-2194, 2006. DOI: http://dx.doi.org/10.1111/j.1467-9620.2006.00778.x

ARTILES, A. J.; KOZLESKI, E. B.; GONZALEZ, T. Para além da sedução da educação inclusiva nos Estados Unidos: confrontando o poder, construindo uma agenda histórico-cultural. Teias, Rio de Janeiro, v. 12, n. 24, p. 285-308, jan./abr. 2011.

ARTILES, A. J.; KOZLESKI, E. B.; WAITOLLER, F. R. Inclusive education on five continents: unraveling equity issues. Cambridge: Harvard Education Press, 2011.

ARTILES, A. J.; TRENT, S. C.; KUAN, L. A. Learning disabilities research on ethnic minority students: an analysis of 22 years of studies published in selected refereed journals. Learning Disabilities Research \& Practice, v. 12, n. 1, p. 82-91, 1997. 
ARTILES, A. J.; WAITOLLER, F.; NEAL, R. Grappling with the intersection of language and ability differences: equity issues for Chicano/Latino students in special education. In: VALENCIA, R. R. (Ed.). Chicano school failure and success: past, present, and future. 3. ed. London: Routledge/Falmer, 2011. p. 213-234.

ASH, T. Freedom \& diversity: a liberal pentagram for living together. The New York Review of Books, v. 22, p. 33-36, 2012.

BOWKER, G. C.; STAR, S. L. Sorting things out: classification and its consequences. Cambridge: MIT Press, 2002.

BULGREN, J. A. et al. The instructional context of inclusive secondary general education classes: teacher's instructional roles and practices, curricular demands, and research-based practices and standards. Learning Disabilities: A Contemporary Journal, v. 4, n. 1, p. 39-65, 2006.

BUNCH, G.; VALEO, A. Student attitudes toward peers with disabilities in inclusive and special education schools. Disability \& Society, v. 19, n. 1, p. 61-76, 2004. DOI: http://dx.doi.org/10.1080/0968759032000155640

CARBADO, D. W.; FISK, C.; GULATI, G. M. After inclusion. Duke Law School - Public Law \& Legal Theory Research Paper Series, Paper No. 210 and University of California, Irvine School of Law - Legal Studies Research Paper Series, Paper No. 4, 2008.

CAVENDISH, W.; ARTILES, A. J.; HARRY, B. Tracking inequality: does policy legitimize the racialization of disability? Multiple Voices, v. 14, n. 2, p. 30-40, 2014.

CROSSLEY, S. The disability kaleidoscope. Notre Dame Law Review, v. 74, n. 3, p. 621-716, 1999.

DARLING-HAMMOND, L. Race, inequality and educational accountability: the irony of "No Child Left Behind." Race, Ethnicity and Education, v. 10, n. 3, p. 245-260, 2007. DOI: http://dx.doi.org/10.1080/13613320701503207

DYSON, A. Inclusion and inclusions: theories and discourses in inclusive education. In: DANIELS, H.; GARDNER, P. (Eds.). World yearbook of education 1999: inclusive education. London: Kogan Page, 1999. p. 36-53.

ENGEL, D. M.; MUNGER, F. W. Rights of Inclusion: law and identity in the life stories of Americans with disabilities. Chicago: University of Chicago Press, 2003. DOI: http://dx.doi.org/10.7208/chicago/9780226208343.001.0001

EPSTEIN, S. Inclusion: the politics of difference in medical research. Chicago: University of Chicago Press, 2007. DOI: http://dx.doi.org/10.7208/chicago/9780226213118.001.0001

EREVELLES, N. Disability and difference in global contexts: enabling a transformative body politic. New York: Palgrave Macmillan, 2011a. DOI: http://dx.doi.org/10.1057/9781137001184 
EREVELLES, N. "Coming out crip" in inclusive education. Teachers College Record, v. 113, n. 10, p. 2155-2185, 2011b.

EVANS, I. M. et al. Peer interactions and social acceptance of elementary-age children with severe disabilities in an inclusive school. Journal of the Association for Persons with Severe Handicaps, v. 17, n. 4, p. 205-212, 1992.

FERGUSON, D. L.; KOZLESKI, E. B.; SMITH, A. Transformed, inclusive schools: a framework to guide fundamental change in urban schools. Washington: Elsevier Science, 2003.

FOUCAULT, M. Disciplinary power and subjection. In: LUKES, S. (Ed.). Power. Oxford: Blackwell, 1986. p. 229-241.

FRY, R. How far behind in math and reading are English language learners? Washington: Pew Hispanic Center, 2007.

GIANGRECO, M. F. et al. "I've counted Jon": transformational experiences of teachers educating students with disabilities. Exceptional Children, v. 59, n. 4, p. 359-359, 1993.

GONZALEZ, T.; HERNANDEZ-SACA, D.; ARTILES, A. J. A search for voice: a review of student voice research. Paper presented at the annual meeting of the American Educational Research Association. San Francisco, 2013.

GOTTFRIED, M. A. Classmates with disabilities and students' noncognitive outcomes. Educational Evaluation and Policy Analysis, v. 36, n. 1, p. 20-43, 2014. DOI: http://dx.doi.org/10.3102/0162373713493130

GRAFF, C. S.; KOZLESKI, E. Calcifying, sorting and segregating: brown at 60. Multiple Voices, v. 14, n. 2, p. 52-67, 2014.

GUSTAFSON, K. Disability, fluidity, and measuring without baselines. Mississippi Law Journal, v. 75, p. 1007-1037, 2006.

HACKING, I. Kinds of people: moving targets. In: MARSHALL, P. J. (Ed.). Proceedings of the British Academy. London: Oxford University Press Inc, v. 151, 2007. p. 285-318. DOI: http://dx.doi.org/10.5871/bacad/9780197264249.003.0010

HAHN, H. Disputing the doctrine of benign neglect: a challenge to the disparate treatment of Americans with disabilities. In: FRANCIS, L. P.; SILVERS, A. (Eds.). Americans with disabilities. New York: Routledge, 2000. p. 269-274.

HANUSCHEK, E.; KAIN, J.; RIVKIN, S. Inferring program effects for special populations: does special education raise achievement for students with disabilities? The Review of Economics and Statistics, v. 84, n. 4, p. 584-599, 2002. DOI: http://dx.doi.org/10.1162/003465302760556431

HARR-ROBINS, J. et al. The inclusion of students with disabilities in school accountability systems (NCEE 2012-4056). Washington: National Center for Education Evaluation and Regional Assistance, 2012. 
HUBER, K. D.; ROSENFELD, J. G.; FIORELLO, C. A. The differential impact of inclusion and inclusive practices on high, average, and low achieving general education students. Psychology in the Schools, v. 38, n. 6, p. 497-504. 2001. DOI: http://dx.doi.org/10.1002/pits.1038

HUNT, P.; FARRON-DAVIS, F. A preliminary investigation of IEP quality and content associated with placement in general education versus special education classes. Journal of the Association of Persons with Severe Handicaps, v. 17, n. 4, p. 247-253, 1992. DOI: http://dx.doi.org/10.1177/154079699201700406

HUNT, P.; GOETZ, L. Research on inclusive education programs, practices, and outcomes for students with severe disabilities. The Journal of Special Education, v. 31, n. 1, p. 3-29, 1997. DOI: http://dx.doi.org/10.1177/002246699703100102

IGLESIAS, E. M.; VALDES, F. LatCrit at five: institutionalizing a postsubordination future. Denver University Law Review, v. 78, p. 1249-1293, 2001.

IDEA. Individuals with Disabilities Education Improvement. Act 2004, Pub. L. No. 108-46. Retrieved on 3 may, 2011 from <http://idea.ed.gov/download/statute.html>.

KAVALE, K. A.; FORNESS, S. R. History, rhetoric, and reality analysis of the inclusion debate. Remedial and Special Education, v. 21, n. 5, p. 279-296, 2000. DOI: http://dx.doi.org/10.1177/074193250002100505

KEOGH, B. K. et al. A system of marker variables for the field of learning disabilities. Syracuse: Syracuse University Press, 1982.

KLINGNER, J. K. et al. Addressing the disproportionate representation of culturally and linguistically diverse students in special education through culturally responsive educational systems. Educational Policy Analysis Archives, v. 13, n. 38, p. 1-40, 2005.

KLINGNER, J. K.; VAUGHN, S. Student's perceptions of instruction in inclusion classrooms: implications for students with learning disabilities. Exceptional Children, v. 66, n. 1, p. 23-37, 1999.

KORENICH, R.; SALISBURY, C. Learning opportunities and performance outcomes in inclusive elementary classrooms: executive summary OERI/IES Project. Chicago: UIC Child \& Family Development Center, 2006.

KOZLESKI, E. B. et al. Teacher education in practice: reconciling practices and theories in the United States context. European Journal of Special Needs Education, v. 28, n. 2, p. 156-172, 2013. DOI: http://dx.doi.org/10.1080/08856257.2013.778114

KOZLESKI, E. B.; JACKSON, L. Taylor's story: full inclusion in her neighborhood elementary school. Exceptionality, v. 4, n. 3, p. 153-175, 1993. DOI: http://dx.doi.org/10.1207/s15327035ex0403 2

KOZLESKI, E. B.; SMITH, A. The complexities of systems change in creating equity for students with disabilities in urban schools. Urban Education, v. 44, n. 4, p. 427-451, 2009. DOI: http://dx.doi.org/10.1177/0042085909337595 
KOZLESKI, E. B.; THORIUS, K. A. K. (Eds.). Ability, equity, and culture: sustaining inclusive urban education reform. New York: Teachers College Press, 2013.

KOZLESKI, E. B.; YU, I. Inclusive education. In: MEYER, L. (Ed.). Oxford bibliographies in education. New York: Oxford University Press, 2016.

KUNC, N. The need to belong: Rediscovering Maslow's hierarchy of needs. In: VILLA, R. A. et al. (Eds.). Restructuring for caring and effective education. Baltimore: Brookes Publishing, 1992. p. 25-39.

KURTH, J. A.; MASTERGEORGE, A. M. Impact of setting and instructional context for adolescents with autism. Journal of Special Education, v. 46, n. 1, p. 36-48, 2012. DOI: http://dx.doi.org/10.1177/0022466910366480

LABAREE, D. F. Public goods, private goods: The American struggle over educational goals. American Educational Research Journal, v. 34, n. 1, p. 39-81, 1997. DOI: http://dx.doi.org/10.3102/00028312034001039

LEE, J.; REEVES, T. Revisiting the impact of NCLB high-statkes school accountability, capacity, and resourxes: State NAEP 1990-2009 reading and math achievement gaps and trends. Educational Evaluation and Policy Analysis, v. 34, n, 2, p. 209-231, 2012. DOI: http://dx.doi.org/10.3102/0162373711431604

LOSEN, D. J. Discipline policies, successful schools, racial justice and the law. In: KAYE, J. S.; DECATALDO, K. R.; LANG, T. A. (Eds.). Keeping kids in school and out of court. New York: New York State Permanent Judicial Commission on Justice for Children, 2012. p. 1-25.

LOSEN, D. J.; ORFIELD, G. Racial inequity in special education. Cambridge: Harvard Education Publishing Group, 2002.

McDERMOTT, R.; EDGAR, B.; SCARLOSS, B. Global norming. In: ARTILES, A.; KOZLESKI, E.; WAITOLLER, F. (Eds.). Inclusive education: examining equity on five continents. Cambridge: Harvard Education Press, 2011. p. 223-235.

McLESKEY, J. et al. Are we moving toward educating students with disabilities in less restrictive settings? Journal of Special Education, v. 46, p. 131-140. 2012. DOI: http://dx.doi.org/10.1177/0022466910376670

MEIER, K.; STEWART, J.; ENGLAND, R. Race, class and education: the politics of second generation discrimination. Madison: University of Wisconsin Press, 1989.

NARAIAN, S. Disability, agency, and context: a differential consciousness for doing inclusive education. Curriculum Inquiry, v. 43, p. 360-387, $2013 . \quad$ DOI: http://dx.doi.org/10.1111/curi.12014

NATIONS' REPORT CARD. Summary of major findings. Disponível em: <http://www.nationsreportcard.gov/reading_math_2015/\#?grade=4>. Retrieved on 20 march. 2016. 
NICHOLS, S. L.; BERLINER, D. Collateral damage. Cambridge: Harvard Education Press, 2007.

No Child Left Behind Act of 2001 (NCLB). PL 107-110. 115 Stat. 1425.

NOGUERA, P. School reform and second-generation discrimination: toward the development of equitable schools. Providence, RI: Essay published by the Understanding Educational Equity and Excellence at Scale Project. Annenberg Institute for School Reform, 2007.

OCHS, E. et al. Inclusion as social practice: Views of children with autism. Social Development, Los Angeles, v. 10, p. 399-419, 2001. DOI: http://dx.doi.org/10.1111/1467$\underline{9507.00172}$

PIJL, S. J.; MEIJER, C. J. W.; HEGARTY, S. Inclusive education: a global agenda. London: Routledge, 1997.

RAGAN, A.; LESAUX, N. Federal, state, and district level English language learner program entry and exit requirements: Effects on the education of language minority learners. Education Policy Analysis Archives, v. 14, n. 20, p. 1-32, 2006. DOI: https://doi.org/10.14507/epaa.v14n20.2006

RAWLS, J. Justice as fairness: A Restatement. Cambridge: Harvard University Press. 2001.

ROBERTS, D.; JESUDASON, S. Movement intersectionality: the case of race, gender, disability, and genetic technologies. DuBois Review, v. 10, p. 313-328, 2013. DOI: http://dx.doi.org/10.1017/s1742058x13000210

RYNDAK, D. L.; FISHER, D. B. The foundations of inclusive education: a compendium of articles on effective strategies to achieve inclusive education. Baltimore, MD: TASH, 1988.

SAILOR, W. Devolution, school/community/family partnerships, and inclusive education. In: SAILOR, W. Whole-school success and inclusive education. New York: Teacher College Press, 2002. p. 7-25.

SAILOR, W. Special education in the restructured school. Remedial and Special Education, $\begin{array}{llllll}\text { Pennsylvania, } & \text { v. } & 12, & \text { p. } & \text { 8-22, nov./dez. } & \text { DOI. }\end{array}$ http://dx.doi.org/10.1177/074193259101200604

SAILOR, W.; GEE, K.; KARASOFF, P. Full inclusion and school restructuring. In: SNELL, M. (Ed.). Instruction of students with severe disabilities. New York: Macmillan, 1993. p. 1-30.

SAUNDERS, A. F. et al. Solving the common core equation teaching mathematics CCSS to students with moderate and severe disabilities. Teaching Exceptional Children, v. 45, n. 3, p. 24-33, jan./fev. 2013. DOI: http://dx.doi.org/10.1177/004005991304500303

SCHEID, T. L.; SUCHMAN, M. C. Ritual conformity to the Americans with Disabilities Act: Coercive and normative isomorphism. In: HARTWELL, S. W.; SCHUT'T, R. K. (Eds.). The organizational response to social problems. Bingley: Emerald Group Publishing, 2001. p. 105-140. DOI: http://dx.doi.org/10.1016/S0196-1152(01)80008-9 
SCHNORR, R. "Peter? He comes and goes...": First graders' perspectives on a part-time mainstream student. The Journal of the Association for Persons with Severe Handicaps, New York, v. 15, n. 4, p. 231-240, 1990. DOI: http://dx.doi.org/10.1177/154079699001500402

SILBEY, S. S. After legal consciousness. Annual Review of Law and Social Science, $\begin{array}{llllll}\text { Cambridge, } & \text { v. } & 1, & \text { p. } & 323-368, & \\ \end{array}$ http://dx.doi.org/10.1146/annurev.lawsocsci.1.041604.115938

SKIBA, R. J. et al. Achieving equity in special education: History, status, and current challenges. Exceptional Children, v. 74, n. 3, p. 264-288, 2008. DOI: https://doi.org/10.1177/001440290807400301

SKRTIC, T. E. The special education paradox: Equity as the way to excellence. Harvard Educational Review, v. 61, n. 2, p. 148-206, abr./jun. 1991. DOI: http://dx.doi.org/10.17763/haer.61.2.0q702751580h0617

SKRTIC, T. M. Power/knowledge and pragmatism: A postmodern view of the professions. In: SKRTIC, T. M. (Ed.). Disability and democracy: reconstructing (special) education for postmodernity. New York: Teachers College Press, 1995. p. 25-62.

SKRTIC, T. M.; SAILOR, W.; GEE, C. Voice, collaboration, and inclusion: Democratic themes in educational and social reform. Remedial and Special Education, v. 17, p. 142-157, 1996. DOI: http://dx.doi.org/10.1177/074193259601700304.

SKRTIC, T. M.; SAILOR, W.; GEE, K. Voice, collaboration, and inclusion: Democratic themes in educational and social reform initiatives. In: MITCHELL, D. (Ed.). Systems and Contexts. London: Routledge Farmer, 2005. p. 214-226.

SLEE, R. The irregular school: exclusion, schooling, and inclusive education. Abingdon, England: Routledge, 2011.

SRIVASTAVA, M.; BOER, de. A.; PIJL, S. J. Inclusive education in developing countries: A closer look at its implementation in the last 10 years. Educational Review, v. 67, n. 2, p. 179195, 2015. DOI: http://dx.doi.org/10.1080/00131911.2013.847061

STAR, S. L.; GRIESEMER, J. Institutional ecologies, translations, and coherence: Amateurs and professionals in Berkeley's museum of vertebrate zoology, 1907-1939. Social Studies of Science, v. 19, p. 387-420, 1989. DOI: http://dx.doi.org/10.1177/030631289019003001

STAUB, D. et al. Four portraits of friendship at an inclusive school. Journal of the Association for Persons with Severe Handicaps, v. 19, $1994 . \quad$ DOI: http://dx.doi.org/10.1177/154079699401900407

SULLIVAN, A. L. Disproportionality in special education identification and placement of English language learners. Exceptional Children, v. 77, p. 317-334, 2011. DOI: http://dx.doi.org/10.1177/001440291107700304

Sullivan, A.; KOZLESKI, E. B. 2009 Part B Annual Performance Report (APR) Analysis: Indicators $9 \&$ 10, Part B. Tempe, AZ: Equity Alliance at ASU, 2009. 
THURLOW, M. L.; KOPRIVA, R. J. Advancing accessibility and accommodations in content assessments for students with disabilities and English learners. Review of Research in Education, v. 39, p. 331-369, 2015. DOI: http://dx.doi.org/10.3102/0091732X14556076

TIMMERMANS, S. Saving lives or saving identities? The double dynamic of techno-scientific scripts. Social Studies of Science, v. 26, p. 767-797, 1996. DOI: https://doi.org/10.1177/030631296026004003

TRENT, S. C. et al. Beyond Brown: Empirical research on diverse learners with or at-risk for specific learning disabilities from 1994 - 2012. Multiple Voices, v. 14, n. 2, p. 12-29, 2014.

U.S. Department of Education. For each and every child - A strategy for education equity and excellence. Washington, D. C., 2013.

UNESCO. Final Report - World conference on special needs education: access and quality. Paris: UNESCO. 1994.

VARENNE, H.; McDERMOTT, R. (Eds.). Successful failure: the school America builds. Boulder, CO: Westview Press, 1999.

VASQUEZ III, E. et al. Empirical research on ethnic minority students: 1995-2009. Learning Disabilities Research \& Practice, v. 26, p. 84-93, $2011 . \quad$ DOI: http://dx.doi.org/10.1111/j.1540-5826.2011.00328.x

WAITOLLER, F. W.; KOZLESKI, E. B. No stone left unturned: exploring the convergence of new capitalism in inclusive education in the U.S. Education Policy Analysis Annuals, v. 23, n. 37, p. 1-33, 2015. DOI: http://epaa.asu.edu/ojs/article/view/1779

WAITOLLER, F.; ARTILES, A. J. A decade of professional development research for inclusive education: a literature review and notes for a sociocultural research program. Review of Educational Research, v. 83, n. 3, p. 319-356, 2013. DOI: https://doi.org/10.3102/0034654313483905

YELL, M. The Law and Special Education. Hoboken: Pearson. 2015.

ZUMETA, R. O. Implementing intensive intervention: how do we get there from here? Remedial and Special Education, v. 36, p. 83-88, $2014 . \quad$ DOI: https://doi.org/10.1177/0741932514558935 